\title{
QUADRINHOS DE SUPER-HERÓI EM SALA DE AULA
}

\section{Comic strips in classroom}

\author{
Gelson Weschenfelder \\ Universidade LaSalle. Canoas, Brasil \\ Correo-e: gellfilo@gmail.com \\ Recibido: 20 de marzo de 2019 \\ Envío a informantes: 26 de marzo de 2019 \\ Aceptación definitiva: $\mathrm{I}$ de abril de 2020
}

Resumo: As histórias em quadrinhos podem auxiliar neste gigantesco problema de nossa educação nacional. Elas podem a se tornar objeto de prática de ensino, na tentativa de introduzir o hábito de leitura e de conhecimento nos alunos. Esta pesquisa apresenta a educação através de outras mídias, a importância das histórias em quadrinhos, o seu aspecto pedagógico, principalmente no que tange ao hábito de leitura e à formação da consciência moral das crianças e dos adolescentes e na construção de sua vida. O fascínio que os personagens exercem, fazem o leitor se prender a leitura deste gênero literário, iniciando assim o hábito pela leitura.

Palavras-Chave: histórias em quadrinhos; leitura; cultura e mídias na educação.

AвsтRact: Comic strips can help this huge problem of our national education. They can become the object of teaching practice in an attempt to introduce the habit of reading and knowledge in students. This research provides education through other media, the importance of comics, its pedagogical aspects, especially regarding reading habits and the formation of moral conscience of children and adolescents and the construction of his life. The fascination that charaters play, make the reader get caught reading this literary genre, thus initiating the habit of reading.

KEY WORDS: comics; reading; culture and media in education. 


\section{I. É um pássaro, um avião, é... O surgimento dos super-heróis}

$\mathrm{S}$ URGIDOS HÁ QUASE 8O ANOS, os super-heróis das histórias em quadrinhos, vêm adquirindo cada vez mais fãs de todas as idades. O gênero de superaventura surgiu em 1938 com a revista Action Comics, na qual nasceu o primeiro super-herói das HQs, o 'Superman'. Este foi criado pelos adolescentes Joe Schuster e Jerry Siegel. Um ano depois surgiu 'Batman', e, em I94I, a 'Mulher Maravilha' e 'Capitão América’. A partir daí, esses super-heróis começaram a ocupar um espaço cada vez maior desde o início deste século (Viana, 2005).

$\mathrm{O}$ aparecimento do personagem Superman, mudou drasticamente o panorama das HQs no cenário mundial. Nascia ali a indústria de quadrinhos e muitos jovens começaram a criar seus estúdios de produção de quadrinhos em um período de economia deprimida. As produções de HQs funcionavam como válvula de escape. Estes jovens perceberam a indigência cultural, emocional e econômica do tempo em que viviam (Braga e Patati, 2006).

O gênero de aventura vem então, substituir os quadrinhos com desenhos caricatos e histórias cômicas, características desde o surgimento das HQs com 'Yellow Kid' em I895. A HQ surge como tira de jornais, e somente em I937, surge o Comic Book, revistas em quadrinhos. Portanto, é somente com o gênero de aventura que o indivíduo, na figura do herói, assume papel predominante. Isso se deve às condições históricas que engendraram o novo gênero, como afirma Viana (2005): "a Crise de 1929 traz a necessidade de um indivíduo forte, resistente, um verdadeiro "herói”» (p. 22). Para Marny (I970), há uma 'divinização do herói', uma necessidade social construída,

produzidas por aqueles que são oprimidos e não conseguem imaginar que são próprios agentes de sua libertação e por isso jogam suas esperanças nos heróis e como estes, na realidade, são praticamente inexistentes, então o herói dos quadrinhos aparece como o seu substituto imaginário (Viana, 2005: 24).

Nove anos após a quebra de Wall Street que provocou uma catastrófica depressão mundial (semelhante ao vivenciado em 2008), quando bancos foram à falência, pessoas perderam seus empregos e lares, a criminalidade cresceu e surgiu na Europa um ditador que prometia grandes mudanças (Adolf Hitler). Segundo Morrison (20I2), o palco estava armado para a resposta da imaginação do Mundo Livre. Surgia ali, neste terreno fértil o gênero das superaventuras e com eles, a necessidade do super-herói. Conforme o autor Chopra (20I2): «esses super-heróis são desesperadoramente necessários para solucionar nossas atuais crises em um mundo tomado por conflitos, terror, guerra, ecodestruição e injustiças sociais e econômicas» (p. I4).

Como se pode observar, o super-herói ganhou vida em meio às crises do século xx (Grande Depressão, início da Segunda Guerra Mundial, etc.). Para Knowles (2008), o povo norte-americano estava com medo por ter experienciado todos estes acontecimentos. Assim, os personagens das HQs de superaventura «proporcionavam conforto e certa fuga da realidade» (p. 23). Os primeiros super-heróis não enfrentavam grandes supervilões, mas ao contrário, em suas primeiras aventuras, eles lutavam contra os vilões que realmente preocupavam as pessoas deste período histórico: gângsteres, políticos corruptos, fascistas e quem se aproveitavam da guerra (ibid.: 24 ). Como exemplo, destaca-se a capa da revista Capitão América \#I em I94I, onde o personagem 
aparece socando o ditador alemão Hitler, um anseio de muitos, antes dos EUA entrarem verdadeiramente na guerra.

\section{Os mitos contemporâneos}

Sobre este tema, deve-se destacar o pesquisador Joseph Campbell (1904-1987), uma das maiores autoridades no campo da mitologia em nosso século. Pesquisador incansável, escritor e professor, dedicou boa parte de sua vida para compreender o mito em diversas culturas humanas. Considerava a mitologia «o canto do universo; a música da imaginação inspirada nas energias do corpo» (Campbell, 20I2).

Sua vasta cultura, adquirida em anos de pesquisas sobre os mitos de inúmeras sociedades, permitiram que formulasse ideias originais sobre a similaridade entre os povos, em sua relação com o cosmos. Tais noções nos convidam a buscar uma nova forma de interpretar a nossa gênese (Pedro, 20I2).

Como sugerido acima, os novos 'mitos' da atualidade são os super-heróis das HQs. Campbell (2012), afirma que contamos histórias para tentar entrar em acordo com o mundo, para harmonizar nossas vidas com a realidade. Esse autor assim como Irwin (2005) argumenta que os super-heróis das HQs trazem em seus enredos, questões que todo ser humano enfrenta em seu dia a dia. Assim, possibilitam compreender melhor nossas ações ou o que devemos realizar. Para Campbell (20I2), os mitos ensinam que se pode voltar para dentro, e captar as mensagens dos símbolos. $\mathrm{O}$ mito segundo o referido autor é a experiência de vida. Precisamos das experiências para darmos saltos em nossas vidas. Ademais, «mitos servem para compreender e relacionar-se com o mundo, para além do meramente visível» (Campbell, 1990: 9).

Os mitos são sonhos do mundo, são sonhos arquetípicos, e lidam com os magnos problemas humanos (ibid.). Os super-heróis das HQs são o espelho da sociedade, «as lutas que Batman trava nas ruas e nos becos de sua cidade são as mesmas que encaramos em nossa própria vida» (Chopra, 2012: 23), e continua:

Com suas provações e seus triunfos, com suas forças e fraquezas, podemos aprender a perceber nossas próprias batalhas cotidianas. Se conseguirmos nos valer das habilidades deles, descobriremos um poço de conhecimento e um guia de vida com profundas implicações para a transformação pessoal e global (ibid.: 24).

Chopra (20I2) afirma que, os super-heróis sabem que a única forma de superar qualquer desafio é voltar para dentro, assim como Campbell afirma acima. Segundo ele, o mito é «a música da imaginação, inspiradas na energia do corpo» (Campbell, 20I2: 23). Segundo a definição do dicionário, os mitos são as histórias dos deuses. Mas para Campbell (20I2) o mito vai além disso, «o que é um deus, senão um sistema de valores que funciona para a vida humana» (p. 24). Portanto, segundo este autor:

os mitos são metáforas da potencialidade espiritual do ser humano, e os mesmos poderes que animam nossa vida animam a vida do mundo [...] Há a mitologia que relaciona você com sua própria natureza e com o mundo natural, de que você é parte, e há a mitologia estritamente sociológica, que liga você a uma sociedade em partículas (ibid.: 24). 
O mito é um código para explicar nossa realidade e assim, propiciar que os indivíduos tenham uma válvula de escape ou um norte diante de enfrentamentos do seu cotidiano. Para Knowles (2008), «só invocamos nossos deuses quando precisamos deles» (p. 24). Se a vida está calma, fácil nós os ignoramos. Os livros proféticos bíblicos (judaico cristão) estão repletos de textos com mostras da história do povo de Israel negligenciando a seu deus em momentos de calmaria social. Da mesma forma podemos fazer uma comparação com os super-heróis das HQs.

A explosão das revistas em quadrinhos causada pela Batmania no final da década de 1980, por exemplo, refletiu o sentimento de verdadeiro terror nas cidades dos Estados Unidos, causado pela proliferação do crack e pela explosão da violência das gangues, acarretada pelo consumo de drogas [...] $\mathrm{Na}$ era Clinton, onde tudo era despreocupação e festa, porém a popularidade dos super-heróis atingiu um nível mais baixo. Tudo isso mudaria em II de setembro de 200 ( $($ bid.: 24).

Para Campbell (2012), precisamos de mitos que se identifiquem com os indivíduos, e suas realidades. Já Morrison (2012) comenta o porquê os super-heróis se tornaram mitos contemporâneos e fazem um grande sucesso. Na opinião desse autor, estes personagens deixam tudo mais divertido, mais fácil de enfrentar.

Será que uma cultura faminta por imagens de otimismo de seu próprio futuro voltou-se para a fonte primária em busca de modelos utópicos? Pode o super-herói de capa e colante ser a melhor representação atual daquilo que todos nós podemos nos tornar, se nos sentirmos merecedores de um amanhã em que grandes virtudes serão fortes o bastante para superar os impulsos destrutivos que tentam desfazer o projeto humano? (Morrison, 2012: 15-16).

Para responder tal questionamento, Morrison (20I2) afirma que as HQs «lidam diretamente com elementos míticos da experiência humana com as quais todos nós podemos fazer um paralelo» (p. I6), algo já afirmado por Campbell (20I2) sobre a jornada do herói. E, afirma ainda que «quando são bons, eles nos ajudam a enfrentar e resolver até as crises existenciais mais profundas. Devíamos ouvir o que eles têm a dizer» (Morrison, 20I2: 16).

\section{A história das críticas à utilização da imagem do super-herói na educação}

Há cerca de cem anos, em I895, surgia a primeira HQ nos EUA'. Mesmo com todo esse tempo de existência, as HQs continuam sendo subestimadas e discriminadas nos meios acadêmicos, sendo consideradas literaturas marginais e sem qualidade.

No início da década de 1920 começaram as primeiras críticas e surgiram movimentos condenando a leitura das HQs ao redor do mundo. No Brasil surgiram as primeiras críticas formais, quando em 1928 a Associação Brasileira de Educadores (ABE) fez um protesto contra os quadrinhos, alegando que esse tipo de literatura «incutia hábitos estrangeiros nas crianças» (Carvalho, 2006: 32).

Há muitos historiadores que garantem que o pioneiro da HQ foi um ítalo-brasileiro, Ângelo Agostini, em 1869. Mas no Oriente, no Japão já se fazia HQ (os Mangás como são chamados por lá), desde 1702. (Ver: CaRvalho, 2006: 23). 
A crise norte-americana de 1929 promoveu uma demanda imaginária pelo super-herói [...]. A necessidade do herói enquanto figura compensadora imaginária vem acompanhada, ao lado da produção de HQ, de um tipo específico de herói: o colonizador (Viana, 2005: 28-29).

Segundo Nildo Viana (2005), a crise contribuiu para uma nova política, a de 'boa-vizinhança', a presença norte-americana a partir de então, se tornou cada vez mais significativa na América Latina, e as HQs de super-heróis eram os novos modelos de inspiração. Esta invasão de cultura (imperialismo norte-americano) assustou os educadores. Uma década depois, aqui no Brasil, a ABE ganhou apoio de diversos Bispos da Igreja Católica, propondo a censura às HQs, sob a alegação de que estas traziam «temas estrangeiros prejudiciais às crianças», dando continuidade à xenofobia (Carvalho, 2006: 32).

Muitos denunciavam o caráter ideológico das HQs, principalmente dos quadrinhos de super-heróis. A era das superaventuras (HQs de super-heróis), surgiu no período que antecedeu a Segunda Guerra Mundial. E é em plena Segunda Guerra Mundial, que este pensamento ganhou seu auge. Até Hitler criticou os quadrinhos norte-americanos, afirmando que, o personagem Super-Homem é judeu.

O Super-Homem não é judeu no sentido correto do termo, já que ele não possui religião (já que não é um ser humano), mas é «judeu» no sentido de que realmente ele é inimigo dos nazistas e defensor dos Estados Unidos, devido ao fato dele simbolizar o «homem-livre» norte-americano. Desta forma, ele assume a característica comum de todos os «inimigos imaginários» criados pelos nazistas, assumindo a forma de mais um «conspirador judeu» (Viana, 2005: 45).

Mas, talvez os nazistas afirmem que o personagem Super-Homem seja judeu, por seu nome de batismo. Esse super-herói se chama Kal-El, que carrega a palavra hebraica 'El', que significa Deus. Para Viana (2005), a emergência da segunda grande guerra e o papel dos Estados Unidos nesta, explicita a inserção do caráter político nos quadrinhos. O mundo dos super-heróis passa a ter, segundo o autor, uma função propagandística de determinados valores hegemônicos na sociedade. A «necessidade de heróis de carne e osso para sacrificar sua vida na guerra criou a necessidade da fantasia dos super-heróis» (ibid.: 45).

E foram inúmeros super-heróis criados neste período, sendo que um dos mais conhecidos é o supersoldado Capitão América, cujo uniforme é composto pelas cores da bandeira dos Estados Unidos. Em sua análise, Viana (2005) desnuda os quadrinhos concluindo que, por trás da aparência inocente das HQs de super-heróis há valores axiológicos (ibid.: 8). Entendamos por 'axiologia', segundo o autor, padrão dominante de valores em nossa sociedade.

Um padrão é de certa forma, uma configuração, uma forma. Um padrão dominante é aquele que possui uma supremacia sobre outros padrões. Um padrão dominante de valores é, então, um padrão de valores que possui supremacia sobre outros padrões de valores. Uma configuração é uma determinada forma que assume os valores, os valores dominantes, que são valores da classe dominante. Os valores dominantes podem assumir diferentes configurações, mas conservam sempre os valores fundamentais correspondentes aos interesses da classe dominante. É por isso que a axiologia é uma determinada configuração dos valores dominantes (ibid., 2002: 84). 
Ao longo dos anos, o consumo de HQs cresceu de forma acelerada, e as críticas não cessavam, principalmente aqui no Brasil.

Em 1944, o Instituto Nacional de Educação e Pesquisa (INEP), órgão ligado ao Ministério da Educação (MEC), apresentou um estudo preconceituoso, sem rigor na apuração ou embasamento criterioso, no qual afirmava que as HQs provocavam «lerdeza mental». Ao que parece, a preocupação do INEP era com o fato de que muitas crianças preferirem ler quadrinhos a livros. Ainda que muitos intelectuais e até mesmo o governo de Vargas elogiassem as HQs, o tal estudo surtiu efeito devastador entre muitos pais e professores, implicando proibições de leitura das HQs e gerando frases repetidas e lembradas por muitas gerações, como «quem lê histórias em quadrinhos fica com o cérebro do tamanho de um quadrinho» (Carvalho, 2006: 32).

Durante o primeiro Congresso Brasileiro de Escritores em 1946, o jornalista e político Carlos Lacerda criticou a proliferação dos quadrinhos. Segundo ele, as HQS eram 'veneno importado', trazendo prejuízo às nossas crianças (ibid.: 33). Ao contrário de Viana (2005) que visualizava nos quadrinhos a 'manifestação imperialista norte-americana', Lacerda percebia a presença de muitos 'comunistas', entre os escritores e desenhistas de quadrinhos norte-americanos.

Somente em 1949, haveria calmaria após estudo do INEP. O Congresso Nacional, naquele ano decidiu intervir no assunto, criando uma comissão para analisar as HQs. Esta comissão foi presidida pelo então deputado federal Gilberto Freire ${ }^{2}$, membro da Comissão de Educação e Cultura da Câmara dos Deputados; e chegou a tais conclusões: as HQs, em si, não são boas nem más, dependem do uso que se faz delas; as HQs ajudam na alfabetização; por meio de seus enredos, elas ajudam os leitores a ajustar suas personalidades à época e ao mundo; as HQs preenchem a necessidade de histórias e aventuras da mente infantil (ibid.: 34 ).

Freire publicou artigos na imprensa brasileira defendendo as HQs. A citação a seguir é de um desses artigos, intitulado "A propósito de histórias em quadrinhos», publicado na Revista O Cruzeiro de 22 de maio de 1954.

[...] fui dos que se colocaram contra o projeto de lei, traçado, aliás, com a melhor das intenções e o melhor dos brasileirinhos, com que ilustres representantes da Nação pretendem dar solução imediata ao problema das más histórias em quadrinhos. Solução violenta: acabando com o mal pela raiz. Tornando-o assunto policial.

Meu ponto de vista foi então o de que nesse particular o mal poderia ser superado extra policialmente pelo bem. A história em quadrinhos em si não era boa nem má: dependia do uso que se fizesse dela. E ela bem que poderia ser empregada em sentido favorável e não contrário à formação moderna do adolescente, do menino ou simplesmente do brasileiro ávido de leitura rápida em torno de heróis e aventuras ajustadas à sua idade mental (Cademartori, 2003: 59).

Tais conclusões trouxeram certa calmaria no cenário nacional com o preconceito contra as HQs. No entanto, isso durou muito pouco, pois outras pesquisas equivocadas, brigas políticas e publicações preconceituosas sobre os quadrinhos ${ }^{3}$, transformariam as HQs em motivo de pânico entre pais e educadores.

Sociólogo, escritor e autor de Casa grande e senzala.

Os jornais de Porto Alegre em 1953, principalmente o Correio do Povo, publicaram uma série de reportagens contra as HQS. 
Entretanto, em 1954, um estudo em território norte-americano, publicado em livro, sob o título Seduction of the Innocent ${ }^{4}$, do psicólogo Frederic Wertham, buscou apresentar de um modo embaçado e preconceituoso a culpa nas HQs, alegando que estas provocavam 'comportamentos anormais's nas crianças. Wertham afirmava que crianças que leem HQS nas quais um Lobisomem morde pessoas, criarão tendências ao canibalismo; histórias nas quais um criminoso insulta uma autoridade e consegue escapar dela, incentivam comportamentos similares, e HQS nas quais um criminoso é mostrado como uma pessoa agradável, em qualquer aspecto, incentivaria os pequenos e jovens leitores a serem marginais. Wertham teria pesquisado dentro de penitenciárias norte-americanas, onde constatou que, criminosos presos, em sua maioria, liam ou leram HQs. Esse fato o levou à conclusão de que o hábito de ler quadrinhos influenciaria o crime.

Atualmente, ainda se escuta que alguns super-heróis, como por exemplo, Batman e Robin, trazem significados homossexuais. Isso tudo começou com o próprio Wertham e suas afirmações infundadas de que as HQs incentivavam as crianças a se tornarem homossexuais. Segundo ele, o caso mais emblemático era a relação entre o personagem Batman com Robin. Batman, de forma pejorativa era visto como um homem mais velho, que vestia um uniforme justo e só batia em homens. Wertham afirmou que Batman fazia isso para uma espécie de processo de negação/compensação. Como o personagem se sentia atraído por homens, e não o reconhecia, transformava tal atração em violência. Ao lado deste super-herói está um adolescente de «uniforme colorido e pernas de fora, pulando e saltando de forma quase coreografada» (ibid:: 35). Este é um equívoco de Wertham, que não pesquisou a origem do personagem. Sabe-se que o super-herói Robin, parceiro de Batman, usa este tipo de uniforme, pois ele e seus falecidos pais eram trapezistas, e este era o tipo de vestimenta que usavam nas apresentações. Ademais, nessa crítica aparece o preconceito puritanista norte-americano em relação às questões de gênero, que levou muitas pessoas a cometerem injustiças e atrocidades contra as populações e casais homoafetivos.

As insinuações de Wertham, diante da dupla de super-heróis Batman e Robin vão além. Afirmava ele que, depois das aventuras noturnas ${ }^{6}$, de volta a mansão Wayne, onde vive o alter ego de Batman, Bruce Wayne, que é mostrado em uma confortável poltrona, vestindo um luxuoso robe e fumando cachimbo, tendo a seus pés o jovem Dick Greyson, alter ego de Robin, observando-o com admiração ${ }^{7}$. Tudo isso em um ambiente luxuoso, recheado de peças decorativas ${ }^{8}$. Batman e Robin são a realização do «sonho homossexual», sentenciava Wertham, que também dizia que a super-heroína Mulher-Maravilha era lésbica, por viver em uma ilha onde só mulheres viviam (ibid.: 36). Novamente aqui, Wertham critica os personagens das HQs, sem conhecer a origem destes. Mulher Maravilha é uma guerreira Amazona, de um povo da mitologia grega, que vivia na ilha de Themyscira. As Amazonas não suportavam a presença masculina. Conta a lenda que em Themyscira era proibida a entrada de homens, pois a rainha Hipólita sofreu a traição de um homem e desde então baniu a entrada deles.

\section{A Sedução do Inocente.}

Entende-se como 'comportamento anormais' tendência ao crime e homossexualismo.

A caça aos criminosos.

7 Para lembrar que Dick, na língua inglesa, significa tanto o apelido de Richard quanto a um apelido para o órgão sexual masculino.

8 Para Wertham, peças decorativas são coisas de homossexuais. 
Anos mais tarde, o próprio Wertham reconheceria que havia exagerado na dose, mas naquele momento, já era tarde demais, pois suas ideias teriam sido por demais divulgadas e digeridas como verdades. O delírio causado pelo livro, fez com que pais e professores estadunidenses queimassem todas as HQs literalmente. O frenesi foi tão grande que, o governo dos EUA teve que intervir, criando um chamado 'código de ética', às HQs. Pouco tempo depois, o Brasil também aderiu a esta censura, criando o seu código de ética dos quadrinhos, onde foram proibidas histórias de terror, nudez, ilustrações provocantes e cenas de amor realistas, bem como se estabelecia que, nas HQs, «a justiça sempre deveria triunfar» (Carvalho, 2006: 37).

Muitos educadores ainda afirmam que a leitura de HQs torna nossos jovens alienados. Antônio Ozaí da Silva (2006), no prefácio do livro Heróis e super-beróis no mundo dos quadrinhos, alega que:

De fato, a leitura das histórias em quadrinhos não transforma necessariamente uma criança, um jovem, num indivíduo militante em prol dos valores capitalistas; mas também não gera necessariamente o militante contestador do sistema capitalista?

A preocupação alarmante de pais e educadores, com todas as críticas e restrições (que vemos ainda hoje), aos temas abordados nas HQs, expressa que estes acreditam que as mesmas provocam uma atitude de preguiça mental ao seu leitor e retardam o processo da abstração e dificultam o hábito de leitura.

O hábito de histórias em quadrinhos aí está, produzindo os seus frutos: uma geração coca-cola, de play-boys e de vadios, avessos a uma vida decente, de trabalho e responsabilidade; por obra e graça dos fadados quadrinhos, uma juventude cresce transviada, sem força de vontade, sem gosto pelo estudo, amante da vida airada e ociosa (Abrahão, 1977: 15I).

Ao longo do tempo, o sistema educacional foi se 'modernizando'. As HQs completaram Ioo anos, mas críticas ainda pairam no ar. Azis Abrahão cita algumas destas críticas:

- [...] não se pode fechar os olhos à notável influência exercida, sobre a criança, pelo exemplo, ao vivo, dos personagens apresentados, agentes do crime e do roubo, em suas façanhas contra a lei, os costumes e a moral.

- A própria ficção, vivida por super-homens, em aeronaves dotadas de exóticos engenhos, movendo-se nos espaços siderais, entre outras fantasmagorias e outras absurdas maravilhas, desvirtuam a imaginação infantil, distanciando-a cada vez mais da realidade [...].

- Habituadas a esse tipo de leitura, reduzida a migalhas e sempre socorrida com as muletas da figura, as crianças acabam por adquirir, certamente, atitude negativa, espécie de preguiça mental, diante da leitura séria, a que no futuro, terão que se sujeitar (I977: I52).

Ainda hoje, é comum que educadores e pais argumentem com sofismas, ligam efeitos a uma causa qualquer, como fez o psicólogo estadunidense Wertham que chegou a conclusões e críticas a partir de entrevistas apenas com pessoas consideradas

9 Prefácio do livro. Ver: Viana (2005: 8). 
criminosas presas que em sua maioria leram quadrinhos. Não se conhece estudo empírico sobre tal relação e, portanto, não se pode afirmar, se as HQs prejudicam ou não as crianças e jovens. Outro exemplo de relação causa-efeito sem evidência de realidade é enfocado por Azis de Abrahão (1977) que afirma que se a maioria dos jovens apresenta grande descaso pelos estudos é porque quando crianças apreciavam as histórias em quadrinhos, relacionando a isso a causa do desinteresse escolar. Se assim fosse, poderia se afirmar que um determinado jovem não tem apetite é porque quando criança ele se alimentava muito de leite; portanto, é o leite, que ingeria na infância, o responsável pela sua falta de apetite (Abrahão, 1977: 153).

\section{As histórias em quadrinhos e seu papel formativo}

A criança ou adolescente, leitor de HQs, espectador de filme no Cinema ou ainda de uma animação na Tv, pode ter no super-herói, um modelo a ser seguido. Não se trata de sair por aí saltando de prédios, fantasiado combatendo o crime, mas ter um modelo de justiça, de fazer o que é correto.

[...] os heróis estimulam nas crianças virtudes como a coragem de enfrentar desafios, vencer os medos, proteger os mais fracos, defender ideais e combater o inaceitável. Neste cenário, eles representam os atributos que os humanos mais admiram em si próprios. Mais do que ídolos, são modelos a serem respeitados e imitados. No entanto, não são desprovidos de medo e, justamente por isso, são fonte de coragem ${ }^{\text {Io }}$.

As HQs tornaram-se referência na formação de opiniões, pois de maneira sutil e perspicaz colocam em debate as questões fundamentais das relações sociais e os dilemas morais com os quais todos os seres humanos normais se defrontam no dia a dia. Estas abordam, na forma exemplar de vivência do personagem, as questões de suma importância enfrentadas pelos seres humanos, tais como a responsabilidade pessoal e social, a identidade pessoal, a diferença; as questões atinentes, à alma, à mente e às emoções humanas, além de problemas bem concretos do cotidiano.

Os quadrinhos possuem uma linguagem de fácil compreensão para seus leitores e no caso de alunos, estes não oferecem resistência em seu uso, pois são relacionadas a uma forma de entretenimento e lazer. Para Calazans (2004), as HQs quando projetadas em sala de aula, como um recurso para complementar o ensino de determinado conteúdo, prendem mais a atenção dos alunos do que qualquer outro recurso (ex: o vídeo), pois permitem que ocorra uma leitura simultânea da página, podendo o leitor captar a ação em todos os seus tempos (ibid.: II).

As HQs se colocam como um meio entre os elementos visual (a imagem) e oral (a palavra): a TV e a literatura. Oferecem chance para que o seu leitor use sua imaginação criadora. Enquanto o Cinema e a TV nos dão imagens prontas, sem possibilidade de retorno, as HQs mostram-nos uma sequência intercalada por espaços vazios, e nosso cérebro cria as imagens e ligação (Lovetro, I993: 66).

A aproximação entre Cinema e os quadrinhos é inevitável, pois os dois surgiram da preocupação de representar e dar a sensação do movimento. Os quadrinhos, como o Mattel).

10 GFK Indicador, Estudo Exploratório do Imaginário Infantil. Agosto 2008 (pesquisa exclusiva para 
próprio nome indica, são um conjunto de uma sequência. O que faz do bloco de imagem é o fato de que cada quadro ganha sentido depois de visto; a ação continua e estabelece a ligação entre as diferentes figuras. Existem cortes de tempo e espaço, mas estão ligados a uma rede de ações lógicas e coerentes (Klava e Cohen, I977: IIO).

A Escola Superior de Administração, Marketing e Comunicação (Esamac) realizou uma pesquisa em 200I, entrevistando um universo de três mil leitores de HQs e apurou que $8, \mathrm{I} \%$ dos leitores começaram a ler gibis ${ }^{\mathrm{II}}$ como parte do processo de alfabetização, sendo que $6 \mathrm{I} \%$ se preocupam com o português das HQs e $5 \mathrm{I} \%$ leem as HQs em outras línguas. A mesma pesquisa apurou ainda que 45, $\mathrm{I} \%$ dos entrevistados liam de uma a cinco revistas por mês; $26,6 \%$, de seis a dez gibis mensalmente; $5,1 \%$ de Io a I5 revistas de HQs; e 17,7\% leem mais de I5 exemplares mensais. Em um país onde poucos leem e a maioria prefere trocar esse hábito pela TV ou o videogame, um meio que mobiliza tamanha capacidade de leitura não deve ser desconsiderado quando se trata da formação de opinião e da cultura, além, é claro, de ser a porta de entrada para outros tipos de literatura e um meio influente para a educação em geral (Carvalho, 2006: 38).

A Confederação Nacional dos Trabalhadores em Educação (CNTE) realizou o projeto Retrato da Escola 2, também em 200I, focando mais de dez estados do Brasil, desenvolvendo uma pesquisa ainda mais ampla do que a da Esamac. Através desse projeto comprovou que, alunos que leem HQs, possuem um maior desempenho do que aqueles que usam apenas livros didáticos, assim sendo, as HQs aumentam significamente à performance do aluno. E ainda, entre os que acompanham quadrinhos, o percentual das melhores notas nas provas aplicadas foi de $17, \mathrm{I} \%$, contra $9,9 \%$ entre os que não leem. Mais ainda, essa pesquisa mostra que professores que leem revistas em quadrinhos obtêm melhor rendimento dos alunos, pois conhecem melhor o universo dos estudantes e se aproximam deles usando exemplos desse universo como paradigma para as aulas (Carvalho, 2006).

$\mathrm{Na}$ rede pública, $36 \%$ dos alunos de leitores de gibis têm proficiência média-alta e alta, contra $31,5 \%$ dos não leitores. Na rede particular, $50 \%$ dos estudantes de educadores que leem gibis têm proficiência alta, contra $45,9 \%$ dos que não leem. Para Calanzans (20I4), as HQs «seduzem os jovens, tornando-os leitores, proporcionando uma leitura espontânea e prazerosa» (p. Io). Aristóteles em sua obra Etica a Nicômaco afirma que «os jovens orientam suas vidas pela emoção e, majoritariamente, buscam o que é prazeroso para si mesmo e o imediato» (Aristóteles, 2007: vIII, II56 aI, 30). Os quadrinhos são o primeiro objeto de literatura escolhido pela criança e pelo jovem. Este não é obrigado a ler, ele busca a leitura, pois as HQs é algo prazeroso. Lovetro (1993) descreve as HQs como,

[...] o primeiro livro de leitura de uma criança, e a cada momento se torna uma força importante na integração das diversas linguagens artísticas. [...] é verdade que até agora ela não tem sido utilizada de forma correta no ensino. Em primeiro lugar por falta de profissionais especializados e também por desinformação de editoras que para fazer economia não contratam pessoas capacitadas e não desenvolvem nenhum estudo sobre como passar informações através das HQs (Lovetro, 1993: 67).

II Gibi foi o título de uma revista brasileira de HQs, cujo lançamento ocorreu em I939. Graças a ela, no Brasil o termo gibi tornou-se sinônimo de «revista em quadrinhos». Na época, Gibi significava moleque, negrinho, porém, com o tempo a palavra passou a ser associada a revistas em quadrinhos e, desde então, virou uma espécie de «sinônimo». 
Ler uma HQ além de ser um hábito saudável, estimula o prazer pelo hábito da leitura. Em geral são os maus leitores que criticam as HQs. Nogueira (2008) destaca algumas vantagens do trabalho com as HQs como o fato de que elas não se dirigem a um público de uma faixa etária específica. Algumas delas são lidas por pessoas de todas as idades, desde crianças da educação infantil até estudantes universitários. Em alguns países europeus aprende-se latim com as histórias de Asterix, traduzidas e publicadas em grande tiragem para esta finalidade. Segundo a mesma autora, o preconceito que existe com relação aos quadrinhos é construído em cima da ideia de que eles são coisas de criança ou, em alguns casos, coisa de menino; há HQs de todos os gêneros e para todos os gostos. Algumas adaptações de clássicos da literatura possuem um argumento tão complexo que são indicadas para adultos com um certo grau de conhecimento literário.

Reproduzindo contexto e valores culturais, segundo José Moysés Alves (200I), as HQs oferecem oportunidades para as crianças ampliarem seus conhecimentos sobre o mundo social. Embora elas tenham sido alvo de críticas, seja pelos conteúdos, seja pela forma como os temas são tratados, a sua leitura nas escolas foi frequentemente considerada como atividade clandestina e sujeita a punições (ibid.).

Os estudantes devem aprender a trabalhar as informações que adquirem através da leitura. O uso das HQs como uma forma de expressão dos estudantes, desafiados a exercitar sua capacidade criativa, acabam por si mesmos a criarem seu próprio conhecimento (Weschenfelder, 20II). Ademais, as HQs ajudam os estudantes a compreenderem melhor o conteúdo apresentado em sala de aula. Para Abrahão (1977), o motivo do interesse genérico das crianças pelas histórias e contos é a necessidade de crescimento mental, e o motivo particular de seu interesse maior pelas histórias em quadrinhos está «nos incentivos que esse tipo de literatura traz à mente infantil, atendendo à sua natureza e às suas necessidades específicas» (p. I49). As HQs sempre foram uma mídia de massa sedutora aos olhos das crianças e jovens, seja pela «atraente mistura de texto e imagem» (Carvalho, 2006: 3I), ou ainda pelas histórias de aventuras de super-heróis.

A seriação de quadrinhos, que se assemelha a uma lenta projeção Cinematográfica, ou a cenas fixas, de uma singela peça de teatro, pode considerar-se, na medida solicitada pela mente infantil, adequada ilustração do texto; na realidade, assume o caráter de verdadeiro relato visual ou imaginário, que sugestivamente se integra com as rápidas conotações do texto escrito, numa forma perfeita identificação e entrosamento das duas formas de linguagem: a palavra e o desenho. Exatamente como convém ao caráter sincrético e intuitivo do pensamento infantil (Abrahão, 1977: 150-15I).

As HQs são um potencial instrumento pedagógico. Assim, hoje o antigo distanciamento entre quadrinhos e a educação se estreitou. Como nos diz Calazans (2004), as HQs são um divertimento com o qual os jovens e adolescentes estão familiarizados e prendem sua atenção pelo prazer. Assim sendo, seu primeiro contato com as linguagens plásticas desenhadas com narrativas, iniciando seu contato com a linguagem $\mathrm{Ci}$ nematográfica e a literatura; "podem ser empregadas como estímulo à aprendizagem trazendo o conteúdo programático à realidade palpável do aluno» (p. 33).

O Ministério da Educação e Cultura (MEC) interpreta as HQs como gênero literário, por mesclar elementos verbais escritos e visuais; uma ferramenta pedagógica, mais atraente que o livro tradicional, que poderia levar seus leitores a outras formas 
de leitura, criando este estímulo (Vergueiro e Ramos, 2009). Para Paulo Freire, a leitura não é somente o livro, é tudo: A «leitura do mundo precede a leitura da palavra» (Freire, 1988). Uma leitura pode levar a outras, assim definem Vergueiro e Ramos (2009) ao afirmar que não são somente as obras da literatura que são importantes para o aprendizado e para as práticas pedagógicas.

Como já advertiu Rousseau, "o educador deve conhecer a criança, é sempre nova e oportuna descoberta» (Abrahão, I977: I4I), este 'conhecer', é saber como é o universo desta criança ou adolescente. Os livros, por muitos motivos, não são objeto de prazer destes, mas as HQs são uma forma de prática de leitura no universo dessa faixa etária. As HQs são um recurso a mais na inserção das crianças no mundo das letras, como explica Nogueira (2008), «depende do professor encontrar o caminho para introduzir o aluno neste universo» (ibid.).

[...] as possibilidades das histórias em quadrinhos, como recurso no currículo escolar, são inúmeras, dependendo do conhecimento e da habilidade profissional do professor para diversificar, questionar e provocar a busca da informação destacada pelo leitor (Giesta, 2006).

A junção entre a imagem e o texto, é uma vantagem para o professor na medida em oferece uma ampla gama de recursos semióticos que podem facilitar seu processo de desenvolvimento cognitivo por um lado, e de outro, pode desenvolver e aguçar sua aptidão para as artes. As HQs por terem mais imagem do que texto não impede sua eficácia educacional (Xavier, 2005).

Para Vygotsky (200I), o educador não deve substituir a linguagem infantil pela adulta, mas antes estimular o desenvolvimento da linguagem de forma progressiva a partir do que esta possui de mais expressivo, artístico e, principalmente lúdico.

Como mencionados anteriormente, as HQs podem ser o primeiro instrumento literário de uma criança, e é ao mesmo tempo algo prazeroso, um divertimento, que trabalha com imaginação. Segundo Coelho (198I), a validação do pensamento mágico, potencializa o desenvolvimento múltiplo da capacidade cognitiva da criança, amplia seu universo simbólico. As páginas dos quadrinhos, que levam o seu leitor a imaginar, criar um universo simbólico, motivam o contato com a leitura.

[...] a inclusão de palavras no campo imagístico implicou numa transformação do seu uso, acrescentando conotações e algumas vezes alterando o seu significado. As palavras sofreram um tratamento plástico (nas HQs; passaram a ser desenhadas; o tamanho, a cor, a forma, a espessura, etc., tornaram-se importantes para o texto. [...] é exatamente nesta concomitância que está a importância dos mencionados transporte e tratamento do texto, nessa relação organizada entre a informação analógica e a abstrata que criam um conjunto novo, possibilitando um conhecimento rápido e preciso (Klawa e Cohen, I977: I22-II3).

Se for através da atividade lúdica que chegamos ao processo de ensino e aprendizagem, por que não através das HQs incentivar a aquisição de hábitos de leitura? Abrahão (1977) se preocupa com os programas de incentivo a leitura, muitas vezes o profissional de educação não está preparado ou não sabe que tipo de publicação usar. Segundo o autor, é preciso considerar que, forçar a criança a desenvolver atividades completamente desligada do seu interesse é exigir desta, o dispêndio de dupla carga 
de energia, pois segundo ele, o trabalho contrariado implica num gasto adicional, relativo aos mecanismos de defesa, uma fuga da tarefa (p. I57).

Segundo Nogueira (2008), as HQs são uma excelente fonte de trabalho e pesquisa, elas podem ser usadas desde a educação infantil, pois as HQs «abrem novos horizontes de aprendizagem para as crianças, pois elas descobrem que, mesmo sem saber ler, podem entender a história através dos desenhos». Vale aqui ressaltar que, além de imagens, as HQs são capazes de passar diversas mensagens ao seu leitor. Por isso a necessidade de pesquisa sobre este objeto (Weschenfelder, 20II).

\section{O super-herói como modelo de inspiração}

O jogo de imitar, segundo Arboleya e Bringmann (2008), constitui-se de uma etapa significativa no processo de desenvolvimento cognitivo e motor das crianças. Os autores com base em Vigotsky afirmam que este jogo de imitação constitui uma fase de importantes descobertas pela forma como a criança começa a conceber sua relação com o meio social (Arboleya e Bringmann, 2008: I28), pois o desenvolvimento do pensamento lógico e da imaginação caminham lado a lado, «... a imaginação é um momento totalmente necessário, inseparável do pensamento realista» (ibid.: I28).

As crianças, muito tempo antes de serem alfabetizadas, muito antes de terem acesso a esses meios de narrativas impressas, familiarizam-se com a leitura e a escrita pelo acesso às histórias dos super-heróis. A influência dos personagens se inicia pela referência que eles são nas práticas de consumo: escolha dos vestuários, nos utensílios imediatos que são motivos temáticos de mochilas e materiais escolares, festas infantis, camisetas, e não podemos nos esquecer das animações da TV, Cinema, quadrinhos e etc. São formas narrativas que as crianças começam a desfrutar desde muito cedo, muito antes de qualquer processo de letramento (Cademartori, 2003: 47). De acordo com Carvalho (2006), as HQs e seus personagens representam mitos, ideias, valores que podem facilitar o enfrentamento da realidade na forma de grandes aventuras, de atos heroicos e símbolos de sucesso e realização.

Os modelos, que representam o leitor, motivam imitações desde a idade infantil, passando pela adolescência, até a fase adulta. Para Klava e Cohen (I977), a fantasia é a realidade da criança, que a manipula como o adulto manipula a sua realidade. Assim ele exercita a sua inteligência em suas abordagens do mundo desconhecido e para ela o mundo é todo desconhecido, convertido provisoriamente num universo fantástico em que ela penetra, e soberana, tudo explica a seu modo e segundo seus desejos. É esta, de fato, a única fase da vida em que o homem é verdadeiramente o 'dono da realidade’, que ele cria, constrói e destrói à sua vontade (Klawa e Cohen, I977: I59).

A criança é qualitativamente e «desenvolvimentalmente» diferente do adulto. Suas necessidades são bem diferentes e são geralmente bem pouco conhecidas, e quase nunca são levadas a sério. A literatura em quadrinhos agrada tanto a crianças como adolescentes, pois constitui um sistema que corresponde rigorosamente a sua natureza profunda, atende as suas necessidades orgânicas e aos seus interesses naturais (ibid.: I64). Aí surgem as ideias de podermos transformá-la num poderoso instrumento pedagógico.

$\mathrm{Na}$ vida real nós damos crédito de modelos virtuosos a personagens históricos como Sócrates e Jesus. Mesmo considerando estas figuras históricas como modelos 
morais, sabemos de tais afirmações por autores que escreveram sobre eles. Tudo que se sabe de Sócrates veio através dos escritos de Platão, e da mesma forma no que se refere a Jesus. O que se sabe dele, de suas palavras e ações, foram os seguidores que o escreveram; os apóstolos. Até que ponto essas figuras históricas foram realmente tão virtuosas, não o sabemos. $\mathrm{O}$ que se sabe é o que se disse sobre elas. «A verdade acerca de modelos morais históricos é quase sempre menos impressionante do que o ideal exagerado, mas muitas dessas pessoas ainda merecem ser imitadas» (Irwin, 2008: II7), como por exemplo, modelos históricos, como Gandhi, Madre Teresa, Buda, etc.

Referindo-me aos modelos morais anteriormente citados, por serem personagens reais, parte da história da humanidade, ainda teriam chance de errar e cair no descrédito. A menos que saibamos tudo sobre a vida de nosso exemplo/modelo, corremos o grande risco de creditarmos virtuosidade para alguém que não mereça tal título. A verdade acerca de quem creditamos ser modelo de virtude é quase sempre menos impressionante do que o ideal desejado (ibid.: II7). Modelos fictícios, como os super-heróis, são melhores modelos do que um personagem real, pois personagens reais sofrem com as fraquezas humanas, ou como Aristóteles fala, com os prazeres. Super-heróis são personagens das páginas das HQs, ou seja, um personagem fictício, ele não está sujeito a estes problemas e tentações (Irwin, 2008). Assim como Sócrates, Jesus, Gandhi, Madre Teresa e etc. que são ícones da atividade virtuosa, os super-heróis também são um ícone da cultura popular Cult.

\section{Super-heróis e as adversidades}

Para a maioria das pessoas, as histórias em quadrinhos de super-heróis se restringem ao entretenimento do grande público, principalmente do público infanto-juvenil. Ao longo dos anos, tais personagens ultrapassaram as páginas das histórias em quadrinhos e invadiram o Cinema, as séries de TV e outras animações. Entretanto, essas histórias em quadrinhos não são simplórios como aparentam, pois não trazem apenas entretenimento ao leitor. Mais do que diversão, essas histórias introduzem e abordam de forma vivida algumas questões de suma importância enfrentadas no cotidiano de pessoas «comuns». São temas ligados à superação de adversidades, construção de identidade pessoal, elementos de ética, moral, justiça, enfrentamento de medos, de situações de violência, entre outros (Weschenfelder, 20II).

A grande maioria dos super-heróis passou ou ainda passa por algum tipo de invulnerabilidade ou adversidade social. Na verdade, quem nunca teria passado por alguma forma de sofrimento? São questões de orfandade, bullying, assassinato dos pais ou de um membro familiar, exploração infantil, violência física e sexual, dramas emocionais, deficiência física etc. Porém, estas adversidades não limitaram estes personagens, muito pelo contrário, estas fizeram com que os mesmos se empoderassem e assim se tornassem os super-heróis.

\section{Considerações finais}

Assim como mencionado anteriormente, no estudo da GFK Indicador (2008), estes personagens das HQs de superaventura, a depender da forma como forem abordados 
em ambientes educacionais, podem estimular diversas virtudes, e ainda servirem como modelos/tutores de resiliência, como é a proposta de investigação desta pesquisa. Além de estimular as crianças e adolescentes a enfrentar seus medos e enfrentar desafios, estes também são impulsionados a proteger os mais fracos ou os que aparentam serem invulneráveis, defender ideais e combater o inaceitável. Mais do que ser ídolos e exemplos de força e coragem, estes personagens são modelos morais.

Há uma necessidade de uma educação moral para os jovens, pois muitas vezes crianças e adolescentes buscam apoio emocionais e psicológicos enquanto vivem sob circunstâncias adversas. Muitas vezes este apoio e seus resultados não são aceitos pela sociedade. Ungar (200I) classifica essa forma de enfrentamento de dificuldades como bidden resilience, e traduzida para o português por Libório e Ungar (20Io) como «resiliência oculta» que por definição

se relaciona a comportamentos específicos associados com perigo (dangerous), afastado dos padrões (devint), deliquência e desordem (em inglês os 4Ds), que funcionam como caminhos não padronizados de acesso à saúde, que podem se apresentar nas vidas de adolescentes e jovens marginalizados de alto-risco (Libório e Ungar, 2010: 48I).

Para Pessoa (20I5), que desenvolveu recentemente uma pesquisa de doutorado sobre o tema acerca de ligações de adolescentes com o uso abusivo e tráfico de drogas, resiliência oculta «é um conceito que seria mais bem esclarecido quando aplicado a grupos que receberam nenhum tipo de intervenção", especialmente jovens que estão em situação de risco e de vulnerabilidade. Estes, se empoderam conflitando a lei, e apresentam problemas de comportamento em espaços sociais, tais como escola, família, ruas e etc.

Como se pode constatar pelas histórias de vida anteriormente descritas de alguns personagens de HQs, estes, além de se empoderarem diante das adversidades vividas, conseguiram expressar resiliência graças a educação moral vivenciada em alguma época de suas vidas. A educação moral de jovens tem como objetivo auxiliá-los a interiorizar valores de uma sociedade e cultura como tarefa pessoal para sua própria realização (Duska e Whelan, 1994). Já para Santos e Trevisol (20I2) o desenvolvimento moral é resultante de um processo contínuo que ocorre por meio das relações estabelecidas entre os indivíduos em diferentes espaços. Trevisol e Toigo (2009) salientam que «[...] a ética e os valores devem ser continuamente trabalhados e reforçados dentro do contexto educacional para que realmente se priorize o desenvolvimento integral dos alunos e formem-se também cidadãos conhecedores de seus direitos e deveres» (p. 7). Aristóteles (2007) afirma que todo jovem necessita de bons exemplos para assim chegar a virtude moral, tornar-se um ser ético, um indivíduo que age reta e corretamente. Weschenfelder (20I4) demonstra em seu trabalho que estes modelos apresentados pelo filósofo grego, podem vir a ser os personagens da ficção das HQs.

\section{Bibliografia}

Abrahão, A. (1977). Pedagogia e quadrinhos. In A. Moya, Shazam! (pp. 137-170). São Paulo: Ed. Perspectiva.

Arboleya, Valdinei e Bringmann, Danieli (2008). Literatura infantil, contação de histórias e mídia: Alternativas metodológicas e prática pedagógica. In $I^{\circ}$ Simpósio Nacional de Educação 
XX Semana da Pedagogia-Unioeste, nov. 2008. Disponível em <http://www.unioeste.br/ cursos/cascavel/pedagogia/eventos/2008/I/Artigo\% 2036.pdf>Capturado em:22/ıo/20IO.

Aristóteles (2007). Ética a Nicômaco. 2. ${ }^{a}$ edição. Tradução Edson Bini. Bauru, sp: Edipro.

Bearry, S.; Greenburger, R.; Teitelbaum, M. e Wallace, D. (2009). The DC Comics Encyclopedia. London: Dorling Kinderley.

Braga, Flávio e Patati, Carlos (2006). Almanaque dos quadrinhos. Rio de Janeiro: Ediouro.

Calazans, Flavio (2004). Histórias em quadrinhos na escola. São Paulo: Paulus.

Cademartori, Ligia (2003). Criança e quadrinhos. In S. Jacoby (org.) A criança e a produção cultural - do brinquedo à literatura. Porto Alegre: Mercado Aberto.

Campbell, Joseph (2007). O herói de mil faces. São Paulo: Pensamentos.

Campbell, Joseph (2008). The hero with a thousand faces. Novato, ca: New World Library. (Original work published 1949).

Campbell, Joseph (2012). O poder do mito. São Paulo: Palas Athena, 29. ${ }^{a}$ ed.

Carvalho, Djota (2006). A educação está no gibi. Campinas, São Paulo: Papirus.

Chopra, Deepak (2012). As 7 leis espirituais dos super-heróis. São Paulo: La Fonte, 2012.

Coelho, Nelly Novaes (198I). A literatura infantil: História-teoria-análise. São Paulo: Instituto Nacional do Livro.

DC. (2009). The DC Comics Encyclopedia. London: Dorling Kinderley.

Forbeck, M. (2015). Marvel Encyclopedia: updated and expanded. London: Dorling Kinderley.

Freire, Paulo (1988). A importância do ato de ler: em três artigos que se completam. 22. ${ }^{a}$ ed. São Paulo: Cortez.

IRWIN, William (org.). (2008). Batman e a filosofia: o cavaleiro das trevas da alma. Tradução: Martha Maluezzi. São Paulo: Madras.

Irwin, William; Morris, Matt e Morris, Tom (2005). Super-heróis e a filosofia: verdade, justiça e o caminho socrático. Tradução: Marcos Malvezzi Leal. São Paulo: Madras.

Johnson, J. K. (2012). Super-history: Comic book superheroes and American Society, 1938 to the present. Jefferson, NC: McFarland.

Klava, L. e Cohen, H. (1977). Os quadrinhos e a comunicação de massa. In Á. Moya, Shazam! (pp. I03-I20). São Paulo: Ed. Perspectiva.

Knowles, Christopher (2008). Nossos deuses são Super-Heróis. Tradução: Marcello Borges. São Paulo: Cultrix.

Lovetro, José Alberto (1993). A linguagem do futuro. In Linguagem e linguagens. São Paulo: FDE, n. I7, 1993 .

Marny, Jacques (1970). Sociologia das histórias em quadrinhos. Porto: Civilização.

Marvel. (2005). Enciclopédia Marvel. Barueri, sP: Panini, 2005.

Marvel. (20I4). Spider-Man-A origem do Homem Aranba. São Paulo: Abril.

Marvel. (2015). Marvel Encyclopedia-updated and expanded. London: Dorling Kinderley.

Morrison, Grant (20I2). Superdeuses. São Paulo: Seoman.

Nogueira, Natania A. (2008). Gibioteca: Ensino, criatividade e integração escolar. Prêmio Professores do Brasil. Disponível em http://www.scribd.com/doc/I40I652I/PREMIO-PROFESSORES-DO-BRASIL. Capturado em: 23/oi/2016.

Nolan, Christopher (2005). Batman Begins. Direção: Christopher Nolan. Warner Bros Picture. I Dvs (I39 min.), color.

Pedro, Arlindenor (20I2). Joseph Campbell, que ajudou a ver além da razão. Disponível em http://outraspalavras.net/brasil/joseph-campbell-que-ajudou-a-enxergar-alem-da-razao/.

Pessoa, Alessandro Gomes (2015). Trajetórias negligenciadas: Processos de resiliência em adolescentes com histórico de envolvimento no tráfico de drogas. Tese (Doutorado). Universidade Estadual Paulista, Faculdades de Ciência e Tecnologia.

Peterson, Scott (2008). Batman: A bistória de Batman. São Paulo: Ed. Fundamentos.

Reinhart, Matthew. DC Super-Heróis (20Io). O poderoso livro pop-up. São Paulo: Salamandra. 
Santos, Roberto Elísio e Vergueiro, Waldomiro (20I5). Análise das teses e dissertações sobre quadrinhos realizadas no século XxI em universidades brasileiras. In Jornadas Internacionais de Histórias em Quadrinhos, 3as. São Paulo. Observatório de Quadrinhos.

Siegel, Jerry e Shuster, Joe (2007). Superman. Crônicas. Rio de Janeiro: Panini Comics/DC Comics, volume I. Edição Histórica.

Thomas, Roy e Lark, Michael (20oI). Superman. A guerra dos mundos. São Paulo: Mythos editora/DC Comics. Edição especial.

Trevisol, M. T. C. e Toigo, L. (2009). Os valores morais na escola: cartografando a compreensão dos professores da educação infantil. In Ix Congresso Nacional de Educação. Educere e III Encontro Sul Brasileiro de Psicopedagogia. esbpp, Curitiba. PR. Anais do Congresso Nacional de Educação. Curitiba. PR: Editora PUCPR.

Vergueiro, Waldomiro e Ramos, Paulo (2009). Quadrinhos na educação: da rejeição a prática. São Paulo: Contexto.

Viana, Nildo (2002). A questão dos valores. Revista Cultura E Liberdade, Ano 2, n. 2, abril.

Viana, Nildo (2005). Heróis e super-heróis no mundo dos quadrinhos. Rio de Janeiro: Achiamé.

Vygotsky, Lev Semenovitch (200I). A construção do pensamento e da linguagem. São Paulo: Martins Fontes, 200I.

Weschenfelder, Gelson (20IIa). Aspectos educativos das histórias em quadrinhos de super-beróis e sua importância na formação moral, na perspectiva da ética aristotélica das virtudes. Dissertação, Unilasalle.

Weschenfelder, Gelson (20IIb). Filosofando com os super-heróis. Porto Alegre: Mediação.

Weschenfelder, Gelson (20I4). Aristóteles e os super-heróis: a ética inserida nas histórias em quadrinhos. São Bernardo do Campo, sp: Garcia edizioni. 
